\title{
Identifying the Critical Success Factors for Low Customized ERP System Implementations in SMEs
}

\author{
Jeroen Wolters \\ University Medical Center Groningen \\ J.O.Wolters@umcg.nl
}

\author{
U. Yeliz Eseryel \\ East Carolina University \\ yeliz@eseryel.com
}

\author{
Deniz Eseryel \\ North Carolina State University \\ deserye@ncsu.edu
}

\begin{abstract}
So far the level of ERP system customization has not been taken into account when identifying critical success factors for ERP implementations in small to medium size enterprises (SMEs). This research empirically tests the influence of the level of system customization on success factors by surveying 216 SMEs. We find that motivation system and project team empowerment are more important in low customized ERP implementations. This study is relevant to both theory and practice as it identifies and analyzes factors contributing to a higher success rate in low customized ERP system implementations in SMEs.
\end{abstract}

\section{Introduction}

Enterprise Resource Planning systems (ERPs) constitute IT innovations that enhance organizational performance through connectivity [1]. These systems aim at processing and facilitating real time organizational transactions. The implementation of ERPs in Small and Medium size Enterprises (SMEs) has increased during the last decade as a result of more established technology and decreased prices [2]. A growing number of vendors focus primarily on SMEs or are expanding their business to the SME sector [2].

Studies confirm that organizational conditions differ between the SMEs and large firms and that company size influences the level of complexity in organizations [3]. There are reasons to believe that for SMEs the ERP implementation success rates are even lower than for larger companies [4]. For smaller organizations, it is more essential that the implementation is successful since they do not have the financial resources to recover from unsuccessful implementations [5].

Research started focussing on critical success factors (CSFs) for ERP implementations in SMEs [1]. Based on a literature review, Soja [6] proposed an extended model containing five categories of $26 \mathrm{CSF}$. Investment plan and implementation experience were found to be especially important for SMEs [6]. The model was further empirically tested in the context of ERP implementations in SMEs.

Most ERP implementations involve some degree of customization of the business processes and the system. Yet, in examining implementation success previous studies have rarely addressed the impact of different levels of customization. The attention was focused on which CSFs lead to implementation success, while ERP implementations have been conceptualized as a homogenous concept disregarding the level of customization. In this paper, we aim to advance our knowledge about factors leading to ERP implementation success in SMEs by taking into account the influence of the level of system customization. We argue that the relationship between CSFs and ERP implementation success is moderated by the level of system customization.

The level of system customization ranges from module selection to code customization. Customization implies changes to the system rather than the organization (business process customization). During an ERP implementation, high and low levels of system customization bring differences in complexity [7], speed of implementation, risk, costs [8] and role changes [10]. Low levels of system customization is advised to minimize the risk in organizations and is mostly done in SMEs [7], implying that a fit is achieved by altering the business processes.

The assumptions and challenges of system and business customization differ so much that a distinction needs to be made between factors leading to the success for both ways of achieving a fit [7]. It is too simplistic to view system customization and business process customization as the same concept since each pose different assumptions and challenges. Different factors leading to implementation success are to be expected for achieving a system-process fit. Despite the occurrence of process and system customization, there is no research that differentiates CSFs for different levels of customization. More 
specifically, no study to our knowledge investigated how system customization affects CSFs influence on implementation success. With this study, we intend to fill in this gap.

In this study, we test the moderating effect of system customization level on the relation between critical success factors [6] and ERP implementation success in SMEs. Our research question is: "What is the effect of the level of system customization on the relationship between CSFs and ERP implementation success in SMEs?"

\section{Literature Review}

\subsection{ERP Implementation Success}

ERP implementation is aimed at improving workflows, better access to information and improved customer satisfaction and needs to be included in the measurement for implementation success [10]. The distinction is made between ERP implementation process success, correspondence success and expectation success [10]. ERP implementation process success is achieved when an IT project is completed within time and budget. Correspondence success means a match between IT systems and the specific planned performances.
To measure success in this study, we use ERP implementation success, referred to henceforth as implementation success, following Hong and Kim [10]. Accordingly we define (ERP) Implementation success as the degree of deviation from project goals in terms of expected costs, time, benefits and system performance. Hence cost overruns, schedule overruns, system performance deficits or the failure in achieving the expected benefits mean lower levels of implementation success. In contrast, on time, on budget ERP implementations which achieved the expected system benefits and expected system performance deliver more implementation success.

\subsection{Critical Success Factors}

Soja [6] identified differences in CSFs for small and large firms, implying that not all factors are equally important during ERP implementations in SMEs. Determining the CSFs for SMEs will increase the likelihood of achieving higher success rates.

The model developed by Soja [6] covers the broad range of mechanisms influencing ERP implementations. The model contains five categories with multiple factors.

Table 1. Factors and their descriptions [6]

\begin{tabular}{|c|c|}
\hline Factor & Factor description \\
\hline \multicolumn{2}{|l|}{ Implementation Participants } \\
\hline Project manager & $\begin{array}{l}\text { Person from the organization who sacrifices most of his working time to oversee the } \\
\text { implementation. }\end{array}$ \\
\hline Motivation system & $\begin{array}{l}\text { There is a motivation system rewarding participation in implementation and on-time task } \\
\text { delivery. }\end{array}$ \\
\hline Co-operation with supplier & $\begin{array}{l}\text { Good co-operation with the system supplier who is competent and offers high levels of } \\
\text { services. }\end{array}$ \\
\hline \multicolumn{2}{|l|}{ Project definition and } \\
\hline Implementation goals & $\begin{array}{l}\text { The definition of implementation goals, defined in economic terms at the organization-wide } \\
\text { level. }\end{array}$ \\
\hline Pre-implementation analysis & $\begin{array}{l}\text { Organization analysis and diagnosis prior to the start of implementation, and the creation of } \\
\text { the organization functioning model with the integrated system support. }\end{array}$ \\
\hline Monitoring and feedback & Information exchange between the project team and end-users. \\
\hline Fast effects & The visible, fast, partial, positive results of the implementation. \\
\hline \multicolumn{2}{|l|}{ Project status } \\
\hline Project team empowerment & $\begin{array}{l}\text { The empowerment of the project team members to make decisions and their high position in } \\
\text { the organization hierarchy. }\end{array}$ \\
\hline IT infrastructure & The appropriate IT infrastructure assured for the implementation project. \\
\hline
\end{tabular}

$\underline{\text { Information systems }}$

Legacy systems The legacy systems adaptation for the operation in the ERP integrated system environment. 
These factors were tested and co-operation with supplier, detailed schedule, fast effects, system reliability and minimal customization were found to significantly influence ERP implementation success. Analysis show that out of the 26 factors, only 10 factors are usable since the other independent variables are highly correlated $(>.30)$. Therefore these 10 factors, presented in Table 1, will be tested in the present study.

\subsection{Customization}

Misalignments between ERP system and organization occur because systems are designed based on standardized business processes. The processes used by ERP systems reflect the market-based perspective of the ERP vendor who seeks economies of scale with its system. Standards by the vendor reduce the variability, which makes them re-useable [11].

Misalignment is defined by Soh and Sia [14] as the differences between the structures embedded in the ERP system and those embedded in the organization (as a reflection of rules, norms and procedures). Any ERP implementation requires a fit between the implemented system and the processes in the organization that the system supports [12].

Organizations that implement ERP systems need to resolve the misalignments between system and the organization. There are two main different approaches for reducing misalignments between the system and organization [7]. The first approach is a fully systemcustomized implementation which is characterised as the most ambitious implementation approach (100\% system customization, $0 \%$ organization process customization) [7]. This method is favoured by multinationals and involves the effort to implement all the modules of the ERP package, without reengineering business processes [13]. This type of implementation is characterized to be very complex.

The second approach is a fully process-customized implementation $(0 \%$ system customization, $100 \%$ organization process customization). Organizations adopt the package as imposed by the developer without modifying the software [20]. A fit between the system and processes is achieved by aligning the business processes to the ERP system. Typically, such a system is used by fewer than 100 users [7]. Fully Processcustomized implementations are characterised by high speed of implementation which reduces both risks and implementation time [8]. Furthermore, future upgrades are better supported and cheaper than those of fully system-customized implementations [9].
The previously described characteristics and alignment possibilities make it clear that the different customization options have different consequences. The fundamental differences between business process and system customization makes it too unrealistic to expect the same CSFs to apply equally to highly-customized ERP system implementations and low-customized ERP implementation. Yet, extant literature disregards these fundamental differences and treats these implementations to be the same. The level of customization influences complexity, speed of implementation, costs, process and role changes. Therefore, we argue that the CSFs for lowcustomized and highly-customized ERP implementations may not be the same, and specifically those for low-customized ERP implementations should be investigated.

\section{Hypothesis development}

The implementation of an ERP system with low levels of customization assumes that the implementing organization is able to adapt itself to the implemented system. In this section, we hypothesize about the nature of this adaptation.

In order to increase the readability of the paper, we formulated the hypotheses by grouping 2 to 4 factors as sub-hypotheses. We tested each factor individually, yet, grouping these factors using Soja's [6] categories makes the paper less tedious and more meaningful to the reader.

The first category of factors in Soja's [6] model is implementation participants. Specifically, a low customized ERP system requires individual and group adaptation to the system. It encourages involvement and collaboration between the recipients and the supplier to increase the adaptation to the system [14]. And, it requires the active presence of a motivation system that ensures the employees' commitment to the implementation project. The ingrained characteristics of low customized implementations, such as members' interaction, and collaboration between the company and supplier and negotiation will have a positive influence on the relationship between participation and the level of implementation success. This leads to the following hypothesis:

H1: The positive influence of implementation participants on implementation success is positively moderated by low levels of customization. In particular, implementation participants include H1(a) project manager, H1(b) motivation system and H1(c) co-operation with supplier. 
The next group of CSFs that influence the implementation success is called project definition \& organization. Next, we discuss the factors that make up the CSF group, namely, implementation goals, preimplementation analysis, monitoring \& feedback, and fast effect.

Since ERP systems are not custom built for particular organizations [14], making a pre-implementation analysis and defining implementation goals are both crucial for tailoring the ERP to organization's needs, and thus achieving implementation success. Soh and Sia [14] showed that strong justification for package modification was found for systems that needed to be adapted because of the organizations' strategy. Yet, for organizations that choose low-customized ERP systems, the lack of flexibility in making justifications to achieve goals identified as a result of pre-implementation analysis will likely hamper the relationship between these CSFs and implementation success. Lowcustomized systems do not meet all the customers' specific needs [21]. The disappointing configurations reduce the effect of implementation goals on implementation success by not completely meeting the needs of the organization. Therefore, we expect the customization level to mediate this relationship.

The next factor in the category project definition \& organization is monitoring and feedback. This is defined as information exchange between end-users and team members [6]. Previous research indicates that for lowcustomized ERP systems, users should be at the forefront in reengineering the business processes, which can be done via monitoring and feedback [1]. But the users who provide this feedback on the system need to know that this feedback will be received and acted upon [15]. In implementations of low customized systems, users' feedback will often not be acted upon due to a focus on keeping customization low. These arguments build a case for the negative influence of low level of system customization on the effect of project definition and organization on implementation success. This leads to the following hypothesis:

H2: The positive influence of project definition \& organization on implementation success, is negatively moderated by low levels of system customization. In particular, project definition \& organization includes H2(a) implementation goals, H2(b) pre-implementation analysis, H2(c) monitoring and feedback and H2(d) fast effect.

The implementation of a low-customized ERP system also influences the relationship between appropriate project planning and successful implementation. With appropriate project planning, we refer to project team empowerment and IT infrastructure.

Project team empowerment is another factor in this category. Organizational members would rather see the system change, than that these members have to changes their routines [14]. Empowerment leads to more motivation [17]. While team empowerment is important for all ERP implementations, we expect that, given the limited ability to customize ERP systems, this factor will be more important for implementation success.

IT infrastructure is the second factor of appropriate project planning category. Customized ERP systems will always fit the current IT infrastructure because they are custom made. The low customized ERP system may not fit the new system [16]. Appropriate IT infrastructures support business flexibility for future changes and increase the capabilities of an organization for quick and economic implementation of new applications [7]. Hence, with IT infrastructures that provide flexibility to the company, the misfits with the non-customized system will be minimal or absent. This effect is increased by lower levels of system customization, which is characterized by high speed of implementation [8]. Low customized systems also support system updates better than customized systems [8]. So the positive influence of appropriate IT infrastructure on successful implementation will be increased by lower levels of system customization because of its speed of implementation and its support for future changes.

Based on these arguments one would expect a positive effect of lower levels of system customization on the relation between project planning and implementation success. This leads to the following hypothesis:

H3: "The positive influence of appropriate project planning on implementation success is positively moderated by low levels of system customization." In particular H3(a) project team empowerment, H3(b) IT infrastructure.

Lastly, we discuss the the positive influence of legacy system on implementation success. With a low customized ERP implementation, the legacy system is ignored, which can lead to underestimating the implementation process as a whole, which may result in exceeding project plans in terms of time, budget, etcetera [18]. With high levels of system customization, this problem will not exist. Low system customized ERP systems decrease the positive 
influence of the legacy system on implementation success. This leads to the following hypothesis:

H4: "The positive influence of legacy system is negatively moderated by low levels of system customization."

\section{Method and Analysis}

Hierarchical linear regression analysis was used to test the hypotheses in this research. The least squares regression method was used to determine whether the relationship between the dependent and independent variables are moderated by a third variable. Hierarchy testing was done to see if the success factors helped explain implementation success more than only the control variable, which is ideal for theory-based hypotheses.

\subsection{Data Collection and Sample Description}

After a pilot study was done, a questionnaire was distributed to individuals based on two criteria. First, the SME had to have an ERP implementation within the last 5 years. Secondly, the person participating in this research needed to be either leading or highly involved in the implementation.

To reach respondents involved in ERP implementations, a general e-mail was sent to 3075 SMEs asking if there were any implementations in the last five years. Contact information was obtained via Orbis Database, which is owned by a Moody's Analytics company, and contains information on over 200 million companies worldwide. We first identified SMEs $(\mathrm{N}<250)$ with e-mail addresses available in Orbis. Responding SMEs were asked for contact information of those involved in ERP implementation. Additionally 54 ERP vendors were contacted and asked if they wanted to assist in distributing the questionnaire. This resulted in 326 contact people involved in implementing ERP systems in different SMEs. These individuals received an email with a link to the anonymous survey using Qualtrics.

The data was gathered during a period of four weeks. One person per organization filled in the questionnaire and this was checked by checking IP-addresses. This led to 219 valid respondents (67\% response rate) and 194 completed surveys $(89 \%)$. The average organization size was 60 employees. The organization size ranged from 2 to 249 employees with a modus of 15 organizations with 20 employees. The organizations operated in the fields of agriculture, machine industry, metal industry, marketing, construction, maritime electro, and other fields.

\subsection{The Measures}

Implementation success is the dependent variable in this research. This concept consists of four partial measures. In this study, following Hong and Kim [10], we measured ERP implementation success in terms of deviation from expected project goals such as cost overrun, schedule overrun, system performance deficit and failure to achieve expected benefits. We adopted a validated seven-item Likerttype scale running from (1) extremely disagree to (7) extremely agree, to measure the extent to which respondents agree with statements about the four items of success. Example item for this concept is: "The ERP project took significantly longer than expected".

To measure system customization we asked five questions, in line with Gattiker and Goodhue [22]. Implementations range on a continuum from high system customization, where the system is altered to high business process customization, which represents changes in the organization. These questions were measured by a seven-item Likert scale running from (1) extremely disagree to (7) extremely agree. An example item is: "The ERP system was altered to improve its fit with this plant".

Originally, Soja [6] identified 26 potential critical success factors. The number of relevant factors has been reduced based on correlations between factors. All factors with high correlations $(>.30)$ have been eliminated, leaving 10 potential critical success factors. To measure the presence of critical success factors during the implementation, respondents expressed their answers using a five-item Likert scale ranging from (1) I extremely disagree to (5) I extremely agree, in line with Soja [6]. In Soja [6], experts were asked if they thought particular factors were important during the implementation and estimated the occurrence of the factors during the implementation. In this research, respondents were asked if these factors were present during the implementation, which is an objective research method. An example item is: "There was good cooperation with the system supplier who is competent and offers high level of services".

Firm size is measured by natural logarithm of the number of employees in the organization and is the control variable in this research, in line with the research of Premkumar and Roberts [23], who found that organization size influences IT adoption. We provide the measurement items and sources in the appendix. Only SMEs (less than 249 employees) are included in this research. 
Table 2. Correlation matrix

\begin{tabular}{|c|c|c|c|c|c|c|c|c|c|c|c|}
\hline & & (A1) & (A2) & (A3) & (B1) & (B2) & (B3) & (B4) & (C1) & (C2) & (D1) \\
\hline (A1) & Project manager & 1.0 & & & & & & & & & \\
\hline (A2) & Motivation system & .11 & 1.0 & & & & & & & & \\
\hline (A3) & Co-operation with supplier & .03 & -.10 & 1.0 & & & & & & & \\
\hline (B1) & Implementation goals & .00 & -.05 & -.2 & 1.0 & & & & & & \\
\hline (B2) & Pre-implementation analysis & -.03 & .07 & .05 & .04 & 1.0 & & & & & \\
\hline (B3) & Monitoring and feedback & .09 & .00 & .07 & .03 & $.22 *$ & 1.0 & & & & \\
\hline (B4) & Fast effects & .06 & .09 & $.29 *$ & .03 & $.25 *$ & $.29 *$ & 1.0 & & & \\
\hline (C1) & Project team empowerment & .09 & -.08 & .14 & .05 & .09 & .12 & $.23^{*}$ & 1.0 & & \\
\hline$(\mathrm{C} 2)$ & IT infrastructure & $.23 *$ & .01 & .09 & .03 & $.24 *$ & $.22 *$ & $.24 *$ & $.15^{* *}$ & 1.0 & \\
\hline (D1) & Legacy system & .07 & $.17 *$ & -.05 & .05 & .06 & $.15 *$ & .02 & -.04 & -.08 & 1.0 \\
\hline
\end{tabular}

*Significant at $\mathrm{P}<.01$

$* *$ Significant at $\mathrm{P}<.05$

\section{Findings}

Before the data could be used to test the hypotheses, validity and reliability were tested. The success measure was normalized and added up to measure the implementation success [10]. All reversed items were recoded. A principal factor analysis on single item scale was done and this measure will be retained for the constructs implementation success and system customization. Multicollinearity diagnostic test was executed to test the inter-correlatedness of the independent variables [19]. Table 2 presents the correlation matrix of the 10 independent variables. Since the presence of factors was measured on a single item scale, no additional analysis needed to be done to prepare the data for hypotheses testing. To test these factors with the interaction terms, these variables are mean centred to minimize the risk for multicollinearity [29].

All scales were reliable, with Cronbach Alphas of .68 for both constructs. The principal factor analysis for implementation success showed values ranging from .65 to .76 and therefore the construct satisfies the criteria. Consequently, all items referring to implementation success were used in the analysis. For system customization the factor analysis showed values ranging between .55 and .77 and thus items measuring the level of system customization were used.

Descriptive statistics show that (D2) project team empowerment (4.20) was the factor most present during ERP implementations in SMEs, followed by (D5) IT infrastructure (3.99), (C4) pre-implementation analysis (3.76) and (C6) monitoring and feedback (3.56). (A4) motivation system (1.68) was the factor that was the least present during ERP implementations in SMEs. For all factors the correlation coefficient between the level of factor occurrence and implementation success was calculated. Interaction terms were created to test the influence of the moderator.

The regression coefficients were used to examine the hypotheses. Multicollinearity diagnostic test indicate that there were no multicollinearity problems in the regression models. Whereas upper-limit VIF scores range from 2.0 to 10.0 [24], VIF scores in this study range between 1.07 and 1.64. Model 1 contains the control variable, size of the organization and has a R-square of .00 and an insignificant $F$ statistic.

Model 2 includes the control variable organizational size and the 10 factors which could be critical success factors for low customized ERP system implementations in SMEs. The R-square of Model 2 is .39 and the $F$ statistic is 8.46 . In Model 3 the 10 interaction terms are added and this model is used to test the moderating variables. The R-square of Model 3 is .48 and the F statistic is 5.8. Model 3 is a significant improvement over Model 2.

The data show that for some of the success factors, the level of system customization has a significant influence. This means that, for implementations with low levels of system customization and thus high business process customization, some factors are more important than for higher levels of system customization. This goes for the factor motivation system where the relation is positively influenced by low levels of system customization $(\beta=.38, \mathrm{p}<.01)$. For low levels of system customization, the positive influence of motivation system on successful 
Table 3. Results from hierarchical regression analyses

\begin{tabular}{|c|c|c|c|c|c|c|c|c|}
\hline & \multicolumn{2}{|l|}{ Model 1} & \multicolumn{3}{|c|}{ Model 2} & \multicolumn{3}{|c|}{ Model 3} \\
\hline & $\begin{array}{r}\text { Coefficient } \\
\text { Estimate }\end{array}$ & S.E & $\begin{array}{r}\text { Coefficient } \\
\text { Estimate } \\
\end{array}$ & & S.E & $\begin{array}{r}\text { Coefficient } \\
\text { Estimate } \\
\end{array}$ & & S.E \\
\hline Implementation success & $4.24 * * *$ & .13 & .06 & & .64 & -.16 & & .68 \\
\hline Level of system customization & & & & & & .01 & & .00 \\
\hline Project manager & & & -.16 & $* *$ & .07 & -.17 & $* *$ & .07 \\
\hline Motivation system & & & .03 & & .11 & .18 & & .11 \\
\hline Co-operation with supplier & & & .27 & $* * *$ & .09 & .19 & $* *$ & .09 \\
\hline Implementation goals & & & -.03 & & .07 & -.01 & & .07 \\
\hline Pre-implementation analysis & & & .16 & & .10 & .22 & $* *$ & .10 \\
\hline Monitor and feedback & & & .03 & & .10 & .04 & & .10 \\
\hline Fast effects & & & .58 & $* * *$ & .10 & .61 & $* * *$ & .10 \\
\hline Project team empowerment & & & .14 & & .11 & .26 & $* *$ & .11 \\
\hline IT infrastructure & & & .22 & & .16 & .22 & & .16 \\
\hline Legacy systems & & & .00 & & .08 & .01 & & .92 \\
\hline Project manager * level of system customization & & & & & & -.06 & & .06 \\
\hline Motivation system * level of system customization & & & & & & .38 & $* * *$ & .10 \\
\hline Co-operation with supplier $*$ level of system customization & & & & & & -.05 & & .08 \\
\hline Implementation goals $*$ level of system customization & & & & & & .07 & & .07 \\
\hline Pre-implementation analysis * level of system customization & & & & & & -.02 & & .11 \\
\hline Monitor and feedback $*$ level of system customization & & & & & & -.14 & & .09 \\
\hline Fast effects $*$ level of system customization & & & & & & .02 & & .10 \\
\hline Project team empowerment $*$ level of system customization & & & & & & .26 & $* *$ & .12 \\
\hline IT infrastructure $*$ level of system customization & & & & & & .10 & & .18 \\
\hline Legacy systems $*$ level of system customization & & & & & & .08 & & .08 \\
\hline Firm Size & .00 & .00 & .00 & & .00 & .00 & & .00 \\
\hline F value & .07 & & 8.46 & & & 5.80 & & \\
\hline $\mathrm{R}^{2}$ & .00 & 1.2 & .39 & & .93 & .48 & & .88 \\
\hline
\end{tabular}

Note: Dependent variable: Implementation success. Model 1; control variable, Model 2; direct relation of CSF on implementation success, Model 3; moderated relations of CSF on implementation success.

S.E: Standard Error

*Significant at $\mathrm{P}<.01$,

** Significant at $\mathrm{P}<.05$.

implementations is increased and makes it more important. This is in line with $\mathrm{H} 1$ and so the empirical findings partially support $\mathrm{H} 1$ and fully support $\mathrm{H} 1(\mathrm{~b})$.

A second factor for which lower levels of system customization increase the positive effect on implementation success, is project team empowerment $(\beta=.26, \mathrm{p}<.05)$. With lower levels of system customization, this factor increases the chance of successful implementation more than in implementations of more customized systems. This is in line with hypothesis 3 and partially supports it. H3(a) is fully supported.

There are no empirical findings to support the negative influence of lower levels of system customization on the relation between project definition and organization on implementation success and thus $\mathrm{H} 2$ is not supported.
There are no findings to support $\mathrm{H} 4$ stating that lower levels of system customization negatively influences the positive influence of legacy systems on implementation success.

\section{Discussion and Conclusion}

The research question in this study was "What is the effect of the level of system customization on the relationship between critical success factors and ERP implementation success in small and medium sized enterprises?" For SMEs implementing a low customized ERP system, this research has shown that there are specific critical success factors leading to successful implementations. This is true for 2 out of the 10 tested factors identified by Soja [6], namely (A2) Motivation system and (C1) Project team empowerment. Our research shows that these two 
factors are more important for the implementation of low customized ERP systems in SMEs.

Motivation system falls within the category of factors for hypothesis 1, which is partially supported. Although non-significant direct relation is found in this research, motivation system is assumed to be important during less customized system implementations. This is the case as users tend to push for system customization because they want to reduce the amount of change they have to make [14]. Participation in less customized implementations is therefore lower than in more customized implementations. Motivation systems which reward involvement will increase participation and will therefore be more important during the implementation of systems that poses lower levels of system customization. Based on the findings, the assumption can be made that this factor is underestimated since it is the factor that was least present in the sample. SMEs implementing a low system customized ERP system can take advantage of this underestimated factor.

The influence of Project team empowerment on implementation success is also higher for cases where system customization is low. The direct relation between project team empowerment and implementation success is non-significant. Yet this factor can be described as important because empowerment leads to motivation, energizes [17] and increases engagement [25]. Organizational members would rather see the system change, than have to changes their routines [14]. This result supports the study of Levin, Mateyaschuk and Stein [26], who found that the empowerment of project team members is key to ERP implementation success, without testing the influence of the implementation strategy on this relation.

\section{Limitations and future research directions}

This research has several limitations. Future research could increase the generalizability of these findings by involving a larger sample size.

Second, Soja [6] selected the factors tested in this study after a thorough literature review focused on SMEs. Yet, other factors might be relevant too, such as the use of steering committee, use of vendors tools [1], leadership and commitment [27] or organizational culture [15]. Hence, future research could include more factors that might be relevant during implementations, or only factors specifically selected for SMEs to see the applicability of these for SME setting.
By adding the implementation strategies as a new concept in the discussion on critical success factors in ERP implementations, many opportunities for future research emerge. Future research should aim at further investigating the concept of low levels of system customization. Also, it remains an interesting empirical question as to whether our findings generalize to larger firms since this research has focused solely on SMEs. It is also interesting to see under which circumstances less system customized systems would add value in larger firms.

In this study, we examined the moderating effect of the level of system customization. Markus, Axline, Petrie and Tanis [13] describe four different phases during ERP implementations. Future research should aim to investigate in which stage each CSF has its crucial role and if there is an influence of different implementation strategies on these factors in different phases. A research like this could provide a better guidance to practitioners in the planning of an ERP implementation.

\section{Theoretical contributions}

This research makes two theoretical contributions. The first is that out of the factors identified by Soja [6], the 10 relevant factors are empirically tested in the SME context. Also, the research takes into account the moderating role of the level of customization on the relationship between CSFs and implementation success.

The second contribution is that this research confirmed that ERP implementations cannot be seen as a generic concept. The results show that the factors influencing ERP implementation success should be examined taking into account the different implementation strategies. It is important to make a distinction between business process and system customization since these implementation strategies have different critical success factors.

\section{References}

[1] T.M. Somers, and K. Nelson, "The impact of critical success factors across the stages of enterprise resource planning implementations," Proceedings of IEEE System Sciences, January 2001, pp. 10.

[2] R. Pinedo-Cuenca, T. Shaw, M. Ahmad, and A. Abbas, "Adoption of ERP systems in SMEs," Proceedings of Conference on Flexible Automation and Intelligent Manufacturing, 2004, pp. 1240-1247.

[3] G. Buonanno, P. Faverio, F. Pigni, A. Ravarini, D. Sciuto, and M. Tagliavini, "Factors affecting ERP system adoption: A comparative analysis between 
SMEs and large companies" Journal of Enterprise Information Management, Emerald Group Publishing Limited, vol. 18 no. 4, 2005, pp. 384-426.

[4] K.A. Olsen, and P. Sætre, "ERP for SMEs-is proprietary software an alternative?" Business Process Management Journal, vol. 13, no. 3, 2007, pp. 379389.

[5] J.R. Muscatello, M.H. Small and I.J. Chen, 2003.” Implementing enterprise resource planning (ERP) systems in small and midsize manufacturing firms," International Journal of Operations \& Production Management, MCB UP ltd, vol. 23, no. 8, 2003, pp. 850-871.

[6] P. Soja, "Success factors in ERP systems implementations: Lessons from practice," Journal of enterprise information management , Emerald Group Publishing Limited, vol. 19, no. 4, 2006, pp. 418433.

[7] A.N. Parr, and G. Shanks, "A taxonomy of ERP implementation approaches," System Sciences, Proceedings of the 33rd Annual Hawaii International Conference, January 4-7, 2000, pp. 10-pp.

[8] M. Nannery, "ERPs? Make mine vanilla," Chain Store Age, vol. 75 , no. 1,1999 , pp. 106 .

[9] S.K. Sia and C. Soh, "An assessment of packageorganization misalignment: Institutional and ontological structures," European Journal of Information Systems, Palgrave Macmillan, vol. 16, no. 5, 2007, pp. 568-583.

[10] K.K. Hong and Y.G. Kim, "The critical success factors for ERP implementation: An organizational fit perspective," Information \& Management, vol. 40, no.1, 2002, pp. 25-40.

[11] S. Sawyer, "A market-based perspective on information systems development," Communications of the ACM, vol. 44, no.11, 2001, pp. 97-102.

[12] D. Robey, J.W. Ross and M. Boudreau, "Learning to implement enterprise systems: An exploratory study of the dialectics of change," Journal Of Management Information Systems, vol. 19, no. 1, 2002, pp. 17-46.

[13] J. Lee, K. Siau and S. Hong, "Enterprise integration with ERP and EAI," Communications of the ACM, vol.46, no.2, 2003, pp. 54-60.

[14] C. Soh and S.K. Sia, "The challenges of implementing "vanilla" versions of enterprise systems," MIS Quarterly Executive, vol.4, no.3, 2005, pp. 373-384.

[15] F. Fui-Hoon Nah, J. Lee-Shang Lau, and J. Kuang, Critical factors for successful implementation of enterprise systems. Business process management journal, MCB UP Ltd, vol. 7, no. 3, 2001, pp. 285296.

[16] W.M. Bulkeley, “A cautionary network tale: Fox-Meyer's high-tech gamble. Wall Street Journal Interactive Edition, 1996.

[17] K.W. Thomas and A.B. Velthouse, "Cognitive elements of empowerment: An "interpretive" model of intrinsic task motivation. Academy of management review, vol 15, no. 4, 1990, pp. 666681.

[18] C.P. Holland and B. Light, "A critical success factors model for ERP implementation", Institute of Electrical and Electronics Engineers software, vol. 16, no 3, 1999, pp. 30.

[19] R. Grewal, J.A. Cote and H. Baumgartner, "Multicollinearity and measurement error in structural equation models: Implications for theory testing," Marketing Science, vol. 23, no. 4, 2004, pp. 519-529.

[20] M.N. Haines, "Understanding enterprise system customization: An exploration of implementation realities and the key influence factors, Information Systems Management," vol. 26, no. 2, 2009, pp. 182-198.

[21] J. Swan, S. Newell and M. Robertson, "The illusion of 'best practice' in information systems for operations management," European Journal of Information Systems, Palgrave Macmillan, vol. 8, no.4, 1999, pp. 284-293.

[22] T.F. Gattiker and D. L. Goodhue, "What happens after ERP implementation: Understanding the impact of interdependence and differentiation on plantlevel outcomes," MIS quarterly, vol. 29, no. 3, 2005, pp. 559-585.

[23] G. Premkumar and M. Roberts, "Adoption of new information technologies in rural small businesses," Omega, vol. 27, no. 4, 1999, pp. 467-484.

[24] J. Cohen, P. Cohen, S.G. West, and L.S. Aiken, "Applied multiple regression/correlation analysis for the behavioral sciences". Routledge, 2013.

[25] G. Jose, and S.R. Mampilly, "Relationships Among Perceived Supervisor Support, Psychological Empowerment and Employee Engagement in Indian Workplaces", Journal of Workplace Behavioral Health, vol. 30, no. 3, 2015, pp. 231250.

[26] R. Levin, J. Mateyaschuk, and T. Stein, "Faster ERP rollouts", InformationWeek, 691, 1998 pp. 24.

[27] M. Al-Mashari, A. Al-Mudimigh and M. Zairi, "Enterprise resource planning: A taxonomy of critical factors", European journal of operational research, vol. 146 no. 2, 2003, pp. 352-364.

[28] R.K. Chandy and G.J. Tellis, "The incumbent's curse? Incumbency, size, and radical product innovation", Journal of marketing, vol. 64, no 3, 2000, pp. 1-17.

[29] L.S. Aiken, S.G. West and R. R. Reno, "Multiple regression: Testing and interpreting interactions", 1991 Sage. 
Appendix: Questionnaire

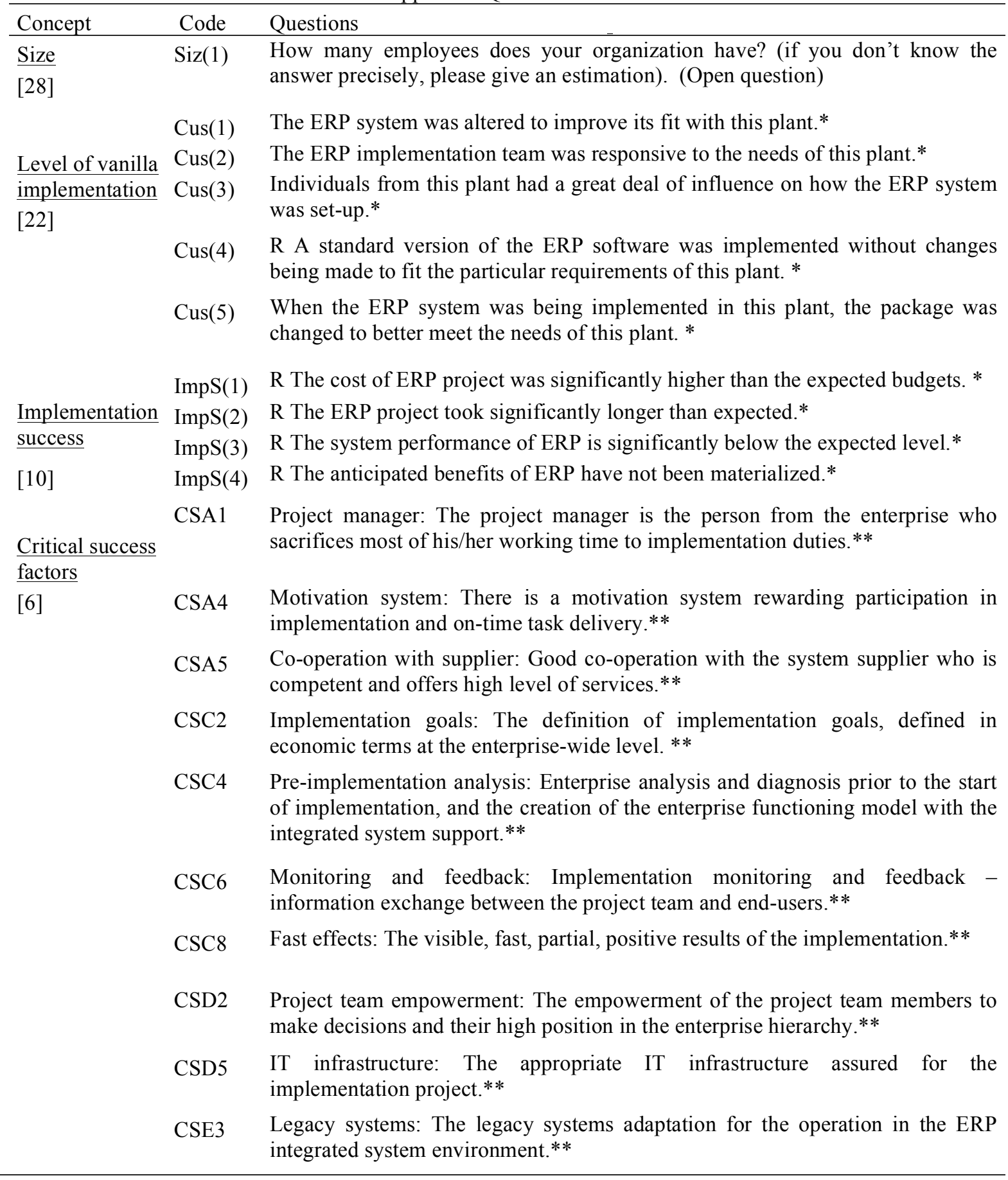

*7-point Likert-scale

**5-point Likert-scale 